\title{
Sammenlikning av data fra Dødsårsaks- registeret og Norsk pasientregister
}

\begin{abstract}
BAKGRUNN Datakvaliteten i Dødsårsaksregisteret er avgjørende for pålitelig dødsårsaksstatistikk. Kreftregisteret bruker data fra Norsk pasientregister til å etterspørre informasjon fra sykehusene om pasienter registrert med kreftsykdom i Norsk pasientregister, men ikke i Kreftregisteret. Vi ønsket å undersøke om data fra Norsk pasientregister også kan nyttiggjøres i Dødsårsaksregisteret.
\end{abstract}

MATERIALE OG METODE Data fra Dødsårsaksregisteret om dødsfall 2009-11 ( $N=124$ 098) ble sammenstilt med data om kontakt med somatiske sykehus og psykiatriske institusjoner siste leveår fra Norsk pasientregister. Dødsårsaker ble gruppert som i standard dødsårsaksstatistikk.

RESULTATER Av 124098 dødsfall skjedde 34,9\% på somatisk sykehus. Totalt $80,9 \%$ av alle avdøde hadde somatisk innleggelse og/eller poliklinisk konsultasjon siste leveår. Andel med sykehuskontakt var høyest når kreftsykdom var dødsårsak. Også ved ukjent/uspesifisert dødsårsak hadde over halvparten sykehuskontakt, men de fleste av disse var kun registrert med polikliniske konsultasjoner. Totalt 5,4\% av alle avdøde hadde hatt opphold i og/eller poliklinisk konsultasjon ved psykiatrisk institusjon siste leveår. Ved selvmord som dødsårsak var andelen $41,8 \%$.

FORTOLKNING Ved mangelfulle opplysninger om dødsårsak kan data fra Norsk pasientregister bidra med informasjon om hvor pasientene har vært behandlet, slik at Dødsårsaksregisteret kan kontakte de aktuelle sykehusene. Den eventuelle nytten begrenses imidlertid av at avdøde med ukjente/uspesifiserte dødsårsaker i mindre grad hadde vært innlagt på sykehus siste leveår.

Datakvaliteten i Dødsårsaksregisteret har vært omdiskutert (1). Mange legeerklæringer om dødsfall har logiske eller innholdsmessige feil $(2,3)$, og Dødsårsaksregisteret er blitt kritisert for å ha en høy andel ikke-spesifikke koder eller koder som ikke kan representere den underliggende dødsårsaken (4). Dette er viktig, ettersom høy kvalitet på data i Dødsårsaksregisteret er en forutsetning for pålitelig dødsårsaksstatistikk, helseanalyse og forskning.

Dødsårsaksregisteret mottar alle legeerklæringer om dødsfall (5), og opplysningene kodes etter internasjonale retningslinjer (6). I tillegg til rutinemessig kobling mot Folkeregisteret blir det innhentet medisinske og rettsmedisinske obduksjons- og toksikologirapporter, og det gjøres kontroller mot Kreftregisteret og Medisinsk fødselsregister (6). I Dødsårsaksregisteret bestemmes så underliggende dødsårsak, definert som enten den sykdom eller skade som innledet rekken av sykdomstilstander som ledet til døden, eller omstendighetene rundt ulykken/ytre årsak som forårsaket den dødelige skaden (6). Det er underliggende dødsårsak som gir grunnlag for dødsårsaksstatistikken.

Norsk pasientregister henter inn pasientadministrative data fra hele spesialisthelsetjenesten (7). Opplysningene omfatter demografiske og medisinske opplysninger. Disse kobles rutinemessig mot Folkeregisteret for kontroll av informasjon om pasientens bosted og innhenting av informasjon om dødsfall.

Både i Dødsårsaksregisteret og Norsk pasientregister benyttes kodeverket International Classification of Diseases, versjon 10 (ICD-10) for koding av henholdsvis dødsårsaker og diagnoser (8).

I Kreftregisteret benyttes data fra Norsk pasientregister til å etterspørre informasjon fra sykehusene for pasienter som er registrert med kreftsykdom i Norsk pasientregister, men ikke i Kreftregisteret. Formålet med denne studien var å undersøke om data fra Norsk pasientregister også kan nyttiggjøres i Dødsårsaksregisteret, spesielt i tilfeller der mangelfullt utfylte legeerklæringer om dødsfall resulterer i bruk av ikke-spesifikke dødsårsakskoder. Vi har sammenstilt opplysninger fra Dødsårsaksregisteret for alle dødsfall i perioden 2009-11 med opplysninger for siste leveår innrapportert fra somatiske sykehus og psykiatriske institusjoner til Norsk pasientregister.

\section{Materiale og metode}

Studien er gjennomført med hjemmel i dødsårsaksregisterforskriften (5) og Norsk pasientregister-forskriften (7).

$\mathrm{Vi}$ hentet opplysninger om alle personer som døde i perioden 2009-11 ( $\mathrm{N}=124$ 098) fra Dødsårsaksregisteret og opplysninger om

\author{
Inger Johanne Bakken \\ inger.johanne.bakken@fhi.no \\ Christian Lycke Ellingsen \\ Anne Gro Pedersen \\ Folkehelseinstituttet \\ Lilian Leistad \\ Helsedirektoratet
}

\section{Jonas Minet Kinge \\ Marta Ebbing}

Folkehelseinstituttet

Stein Emil Vollset

Folkehelseinstituttet

og

Institutt for global helse og samfunnsmedisin Universitetet i Bergen

e-tab 3 finnes i Tidsskriftets elektroniske utgaver

ar

Engelsk oversettelse på www.tidsskriftet.no

\section{HOVEDBUDSKAP}

I løpet av siste leveår hadde fire av fem vært innlagt eller til poliklinisk konsultasjon ved somatisk sykehus, mens én av 20 har vært i kontakt med institusjon innen psykisk helsevern

Ved manglende eller ufullstendige opplysninger i dødsmeldingen til Dødsårsaksregisteret kan data fra Norsk pasientregister bidra med informasjon om hvor pasientene har vært behandlet, slik at Dødsårsaksregisteret kan kontakte de aktuelle sykehusene eller institusjonene

Eventuell nytte av slike data i Dødsårsaksregisterets kvalitetssikringsarbeid begrenses av at informasjonsomfanget i Norsk pasientregister er lavest for dem med ukjent eller uspesifisert dødsårsak 


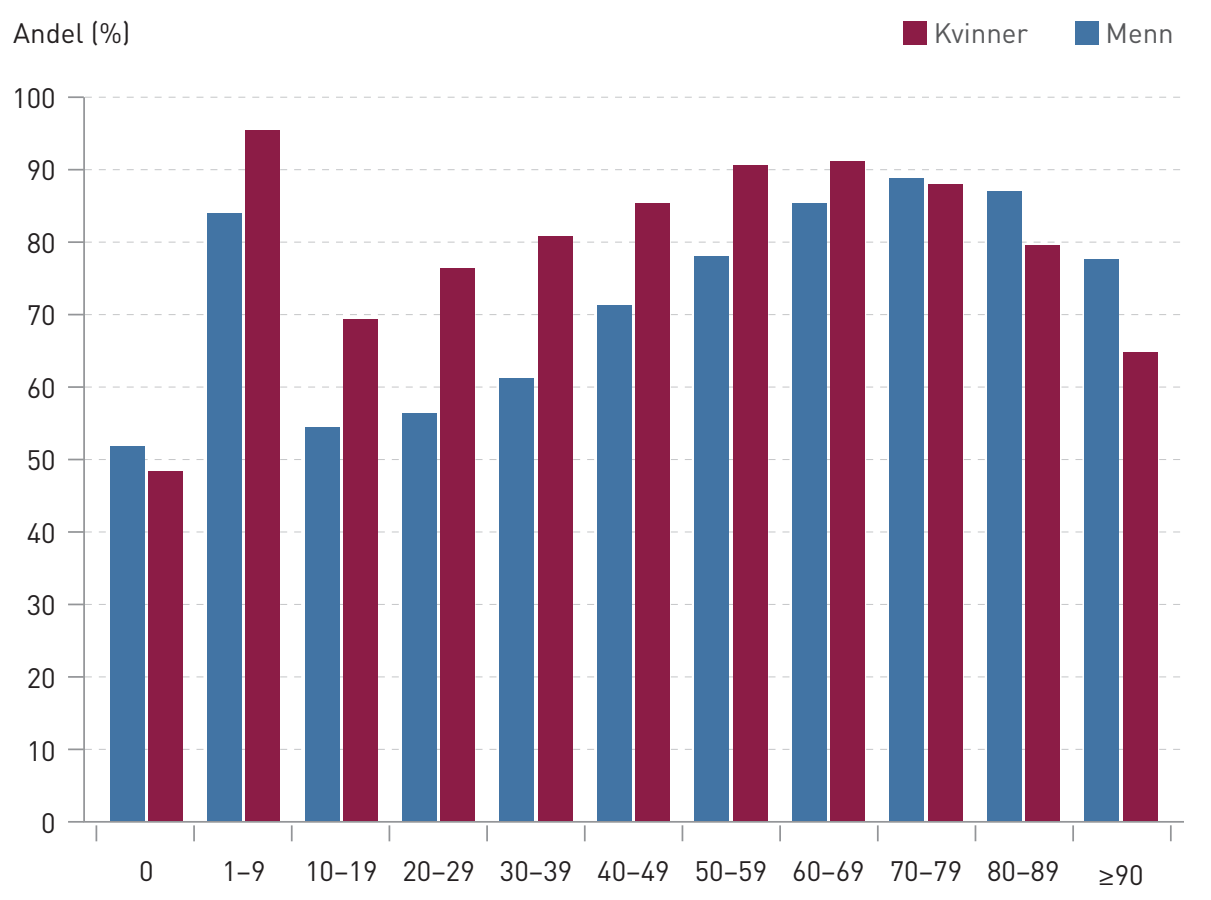

Alder (år)

Figur 1 Andel som har hatt kontakt med somatisk sykehus siste leveår blant alle som døde i perioden 2009-11 ( $N=124$ 098), fordelt på aldersgrupper og kjønn

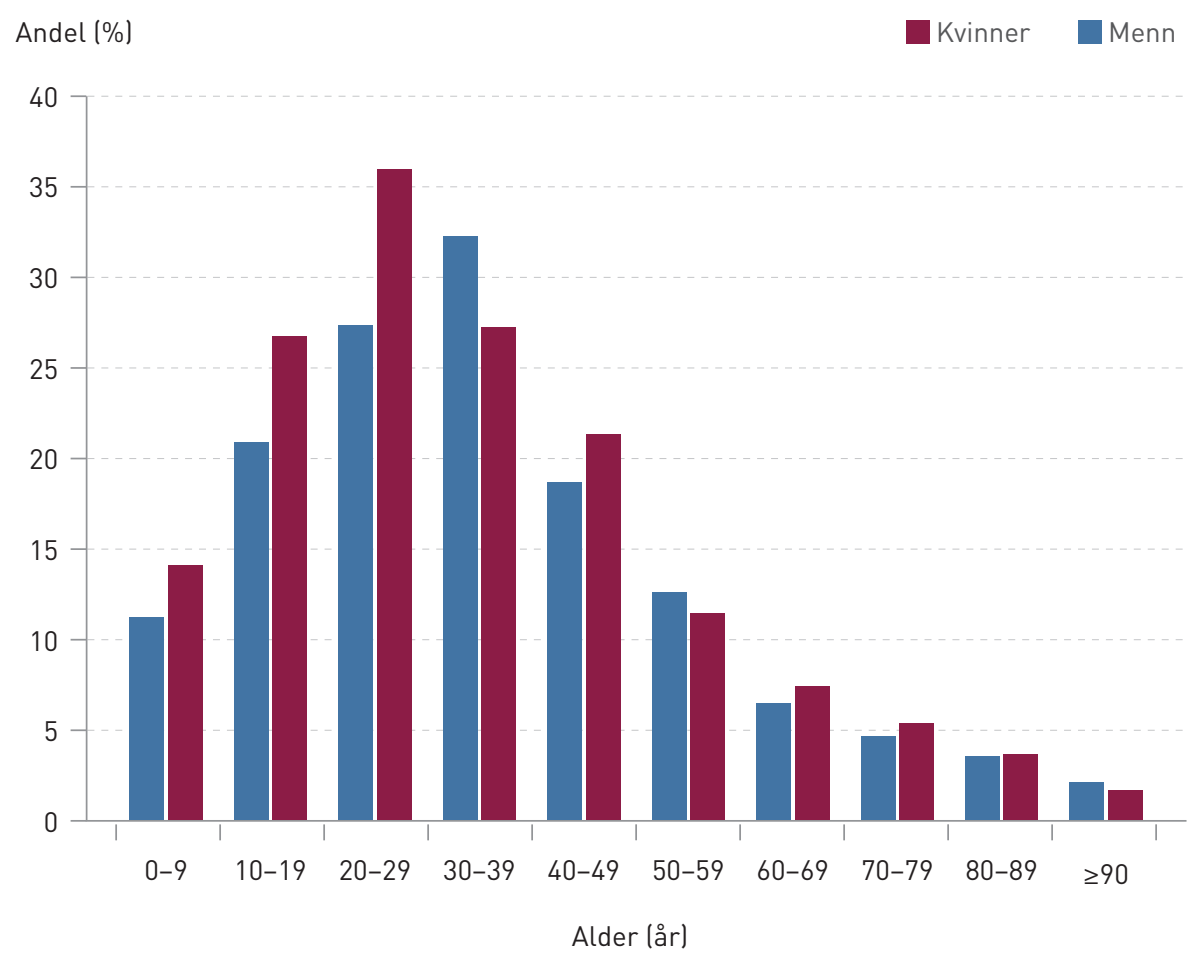

Figur 2 Andel som har hatt kontakt med psykiatrisk institusjon siste leveår blant alle som døde i perioden 2009-11 ( $N=124$ 098), fordelt på aldersgrupper og kjønn alle døgnopphold, dagopphold og polikliniske konsultasjoner i somatiske sykehus og psykiatriske institusjoner siste leveår fra Norsk pasientregister. Vi inkluderte totalt 899265 registreringer fra somatiske sykehus og 51933 registreringer fra psykiatriske institusjoner. I analysene har vi gruppert døgnopphold og dagopphold som innleggelser. Opplysninger fra Norsk pasientregister ble hentet ut ved hjelp av fødselsnumre oversendt fra Dødsårsaksregisteret. Fødselsnumre ble først kryptert og deretter erstattet med løpenumre som var generert i Dødsårsaksregisteret. Analysefilene inneholdt ikke på noe tidspunkt lesbare fødselsnumre.

Dødsfall i sykehus ble definert ved at pasientens siste kontakt (døgn-/dagopphold eller poliklinisk konsultasjon) i Norsk pasientregister var registrert med utskrivningstilstand «som død».

Vi grupperte underliggende dødsårsak etter Europeisk kortliste (6). Denne listen brukes i internasjonalt dødsårsaksstatistikkarbeid og omfatter 17 hovedgrupper og 48 undergrupper. I vår fremstilling har vi inkludert alle hovedgruppene med unntak av «sykdommer i svangerskap, fødsel og barselseng» og «visse tilstander, begynnelse perinatalt». Disse to gruppene utgjorde til sammen bare 267 personer. Vi har i tillegg analysert etter de ti største undergruppene fra Europeisk kortliste samt undergruppen «demens og Alzheimers sykdom» som benyttes i norsk dødsårsaksstatistikk. Totalt er det 11 undergrupper som inngår. ICD-10-kodene for grupperingene er oppgitt i tabell 1 og tabell 2.

Studien er rent deskriptiv. Datasammenstillinger og analyser er gjennomført ved hjelp av statistikkprogrammet Stata.

\section{Resultater}

Kontakt med somatisk sykehus og psykiatrisk institusjon siste leveår Etter kjønn og alder. I alt 43250 (34,9\%) av alle som døde var registrert med dødsfall på somatisk sykehus (tab 1). Det var store variasjoner i kjønn og alder (data ikke vist). Av det samlede antallet som døde i perioden 2009-11 var 100418 personer (80,9\%) registrert med minst én innleggelse eller poliklinisk konsultasjon i somatisk sykehus siste leveår (tab 1), med store variasjoner i kjønn og alder (fig 1). En svært liten andel av alle avdøde $(0,2 \%)$ var registrert med dødsfall i psykiatrisk institusjon (tab 1). Tabellen viser videre at totalt $6742(5,4 \%)$ hadde minst én innleggelse eller poliklinisk konsultasjon i psykiatrisk institusjon siste leveår. Vi observerte store forskjeller med kjønn og alder (fig 2).

Etter hovedgruppe av dødsårsaker. Det var store forskjeller mellom hovedgruppene av dødsårsaker $\mathrm{i}$ andel dødsfall på somatisk sykehus (tab 1). Den laveste andelen ble ob- 
Tabell 1 Opplysninger fra Norsk pasientregister om kontakt med somatisk sykehus og psykiatrisk institusjon siste leveår for personer som døde i perioden 2009-11, etter hovedgruppe av dødsårsaker

\begin{tabular}{|c|c|c|c|c|c|c|c|}
\hline \multirow[b]{2}{*}{ Hovedgruppe ${ }^{1}\left(I C D-10-\right.$ koder $\left.^{2}\right)$} & \multicolumn{4}{|c|}{ Somatisk sykehus } & \multicolumn{3}{|c|}{ Psykiatrisk institusjon } \\
\hline & $\mathrm{N}$ & $\begin{array}{c}\text { Dødsfall } \\
\text { i sykehus } \\
(\%)\end{array}$ & $\begin{array}{c}\text { Innleggelse } \\
\text { og/eller } \\
\text { poliklinikk } \\
\text { (\%) }\end{array}$ & $\begin{array}{l}\text { Kun } \\
\text { poli- } \\
\text { klinikk } \\
(\%)\end{array}$ & $\begin{array}{c}\text { Dødsfall } \\
\text { i institusjon } \\
(\%)\end{array}$ & $\begin{array}{c}\text { Innleggelse } \\
\text { og/eller } \\
\text { poliklinikk } \\
(\%)\end{array}$ & $\begin{array}{c}\text { Kun } \\
\text { poli- } \\
\text { klinikk } \\
(\%)\end{array}$ \\
\hline Totalt & 124098 & 34,9 & 80,9 & 8,5 & 0,2 & 5,4 & 3,4 \\
\hline Infeksjonssykdommer (A00-B99) & 2846 & 53,7 & 85,3 & 4,2 & 0,1 & 4,8 & 3,1 \\
\hline Svulster (C00-D48) & 33087 & 43,8 & 97,4 & 2,2 & 0,0 & 3,7 & 2,7 \\
\hline $\begin{array}{l}\text { Sykdommer i blod/bloddannende organer, } \\
\text { forstyrrelser i immunsystemet (D50-D89) }\end{array}$ & 420 & 43,6 & 88,1 & 3,6 & 0,0 & 5,2 & 3,1 \\
\hline Stoffskiftesykdom (E00-E90) & 3037 & 20,6 & 74,7 & 10,5 & 0,2 & 6,2 & 3,8 \\
\hline Psykiske lidelser (F00-F99) & 5897 & 5,1 & 50,3 & 11,7 & 0,2 & 8,5 & 5,3 \\
\hline Sykdommer i nervesystem og sanseorganer (G00-H95) & 4860 & 16,4 & 62,7 & 10,9 & 0,1 & 8,5 & 5,6 \\
\hline Sykdommer i sirkulasjonsorganene (100-199) & 39594 & 35,3 & 78,3 & 8,1 & 0,1 & 3,6 & 2,4 \\
\hline Sykdommer i åndedrettsorganene (J00- J99) & 12032 & 38,9 & 81,6 & 6,6 & 0,1 & 4,8 & 3,1 \\
\hline Fordøyelsessykdommer (K00-K93) & 3839 & 61,7 & 90,5 & 2,8 & 0,1 & 5,5 & 3,6 \\
\hline Sykdom i hud og underhud (L00-L99) & 269 & 33,1 & 81,8 & 7,1 & 0,0 & 6,7 & 4,5 \\
\hline $\begin{array}{l}\text { Sykdom i skjelett-muskel-system og bindevev } \\
\text { (M00-M99) }\end{array}$ & 772 & 41,6 & 86,7 & 6,2 & 0,1 & 4,7 & 3,5 \\
\hline $\begin{array}{l}\text { Sykdommer i urinveier og fordøyelsesorganer } \\
\text { (N00-N99) }\end{array}$ & 2770 & 36,9 & 85,7 & 5,2 & 0,0 & 4,0 & 2,5 \\
\hline Medfødte misdannelser (Q०0-Q99) & 386 & 41,2 & 71,8 & 4,7 & 0,3 & 10,1 & 9,3 \\
\hline Symptomer og ubestemte tilstander (R00-R99) & 6317 & 6,5 & 55,1 & 14,2 & 0,1 & 4,4 & 2,6 \\
\hline Voldsomme dødsfall (V01 - Y89) & 7705 & 28,6 & 73,4 & 11,0 & 1,3 & 20,4 & 8,8 \\
\hline
\end{tabular}

'I henhold til europeisk kortliste (5). Gruppene «Sykdommer i svangerskap, fødsel og barselseng» og «Visse tilstander, begynnelse perinatalt» (totalt 267 personer) er utelatt

${ }^{2}$ International Classification of Diseases, versjon 10

servert når psykiske lidelser og atferdsforstyrrelser var angitt som dødsårsak $(5,1 \%)$, etterfulgt av symptomer og ubestemte tilstander $(6,5 \%)$. Vi fant også store forskjeller når det gjaldt kontakt med somatiske sykehus siste leveår. Lavest var andelen blant personer med psykiske lidelser og atferdsforstyrrelser som dødsårsak (tab 1).

Andelen dødsfall i psykiatrisk institusjon var lav $\mathrm{i}$ alle hovedgruppene, med 1,3\% $\mathrm{i}$ gruppen voldsomme dødsfall som den høyeste (tab 1). Andelen som hadde vært i kontakt med psykiatrisk institusjon siste leveår var høyest $\mathrm{i}$ hovedgruppen voldsomme dødsfall $(20,4 \%)$ (tab 1).

Etter undergruppe av dødsårsaker. Vi fant videre store forskjeller mellom undergruppene $\mathrm{i}$ andelen dødsfall på somatiske sykehus (tab 2). Lavest var andelen for personer med demens og Alzheimers sykdom som dødsårsak (3,9\%), etterfulgt av de med ukjente og uspesifiserte tilstander (7,3\%). I kreftrelaterte undergrupper fant vi at nesten alle personer var registrert på somatisk sykehus siste leveår (94,7-99,2\%). Andelen var betydelig lavere blant personer med demens eller Alzheimers sykdom som dødsårsak $(48,3 \%)$ og blant personer med ukjente eller uspesifiserte dødsårsaker (57,1 \%). I alle undergrupper var det relativt uvanlig å kun ha hatt poliklinisk konsultasjon, men ingen innleggelser siste leveår. Unntaket er gruppen med ukjent/uspesifisert dødsårsak, der dette gjaldt $42,9 \%$ av de avdøde.

Vi gjorde tilsvarende analyser for opphold i psykiatriske institusjoner siste leveår. I alle undergrupper, med unntak av selvmord, var andelene for kun poliklinisk kontakt relativt lik de totale andelene for kontakt med psykiatrisk institusjon (e-tab 3). I undergruppen selvmord var 4,6\% registrert med dødsfall i psykiatrisk institusjon, 41,8\% var registrert med innleggelse og/eller poliklinisk konsultasjon og 15,2\% var kun registrert med poli- klinisk kontakt siste leveår. Totalt 54,6 \% av alle kvinner og 36,8\% av alle menn med selvmord som dødsårsak hadde hatt kontakt med psykiatrisk institusjon siste leveår. For kvinner var andelen høyest $\mathrm{i}$ aldersgruppen 20-49 år (61\% totalt), mens andelen for menn var høyest $i$ aldersgruppen 30-39 år $(46 \%)$.

\section{Dødsårsak sammenholdt med diagnosekoder}

Til sist sammenholdt vi underliggende dødsårsak med diagnosekoder innrapportert for siste leveår til Norsk pasientregister fra somatisk sykehus ( $\operatorname{tab} 2$ ) og psykiatriske institusjoner (e-tab 3) for de utvalgte undergruppene av dødsårsaker. For kreftsykdommene fant vi i stor grad at koder tilsvarende dødsårsakskode også var registrert fra somatiske sykehus i Norsk pasientregister $(85,6-91,1 \%)$, mens dette sjeldnere var tilfellet for sykdommer i sirkulasjonssystemet. Kodene tilhørende 
Tabell 2 Opplysninger fra Norsk pasientregister om kontakt med somatisk sykehus siste leveår for personer som døde i perioden 2009 - 11 etter utvalgte undergrupper av dødsårsaker

\begin{tabular}{|c|c|c|c|c|c|}
\hline Undergruppe ${ }^{1}\left(I C D-10-k_{0}\right.$ der ${ }^{2}$ ) & N & $\begin{array}{l}\text { Dødsfall } \\
\text { i sykehus } \\
(\%)\end{array}$ & $\begin{array}{l}\text { Innleggelse } \\
\text { og/eller } \\
\text { poliklinikk } \\
\text { (\%) }\end{array}$ & $\begin{array}{l}\text { Kun } \\
\text { poliklinikk } \\
(\%)\end{array}$ & $\begin{array}{c}\text { Tilsvarende diagnosekode } \\
\text { registrert i somatisk } \\
\text { sykehus siste leveår } \\
(\%)\end{array}$ \\
\hline Totalt & 124098 & 34,9 & 80,9 & 8,5 & - \\
\hline Tykktarmskreft, endetarmskreft (C18-C21) & 4689 & 40,0 & 97,0 & 3,0 & 86,3 \\
\hline Kreft i bukspyttkjertel (C25) & 1940 & 44,2 & 99,2 & 0,8 & 89,7 \\
\hline Lungekreft (C32-C34) & 6521 & 50,7 & 99,1 & 0,9 & 91,1 \\
\hline Brystkreft (C50) & 1965 & 41,4 & 94,7 & 5,3 & 85,6 \\
\hline Prostatakreft (C61) & 3143 & 31,1 & 95,5 & 4,5 & 87,1 \\
\hline Kreft i lymfatisk/bloddannende vev (C81-C96) & 2605 & 59,1 & 97,7 & 2,3 & 90,9 \\
\hline Iskemisk hjertesykdom (I20-125) & 15554 & 37,7 & 78,5 & 21,5 & 50,8 \\
\hline $\begin{array}{l}\text { Andre hjerte- og karsykdommer lekskl. revmatiske } \\
\text { og hjerteklaffsykdommer) (I30-I33, I39-152) }\end{array}$ & 8467 & 24,4 & 76,0 & 24,0 & 55,1 \\
\hline Karsykdom i hjernen (160-169) & 9733 & 36,1 & 77,5 & 22,5 & 56,6 \\
\hline Ukjent, uspesifisert (R96-R99) & 4735 & 7,3 & 57,1 & 42,9 & 1,1 \\
\hline Selvmord (X60-X84, Y87.0) & 1721 & 8,4 & 29,6 & 16,2 & 7,7 \\
\hline
\end{tabular}

undergruppen ukjent og uspesifisert dødsårsak er ugyldige koder i Norsk pasientregister og er i liten grad registrert der $(1,1 \%$ for somatiske sykehus).

\section{Diskusjon}

I denne deskriptive studien så vi at blant dem som døde i perioden 2009-11 hadde fire av fem vært innlagt og/eller hatt poliklinisk konsultasjon ved somatisk sykehus siste leveår. Andelen med kontakt med psykiatrisk institusjon var betydelig lavere.

Andelen som hadde hatt kontakt med somatisk sykehus siste leveår var relativt lav blant gutter/menn i aldersgruppene 10-29 år. Dette har sannsynlig sammenheng med at det i disse aldersgruppene er en større andel som dør som følge av ytre årsaker.

Vi fant at om lag halvparten av personer som hadde demens og Alzheimers sykdom som underliggende dødsårsak hadde innleggelse og/eller poliklinisk konsultasjon siste leveår, med en svært liten andel dødsfall på somatisk sykehus. Dette stemmer med opplysninger fra Dødsårsaksregisteret som viste at de aller fleste i denne gruppen døde på sykehjem (data ikke vist).

Blant personer med ukjente og uspesifiserte dødsårsaker hadde over halvparten vært i kontakt med somatisk sykehus siste leveår. De aller fleste av disse var imidlertid regi- strert med kun polikliniske konsultasjoner, noe som kan begrense den eventuelle nytten av å innhente data fra somatiske sykehus som supplement til dødsmeldingen i slike tilfeller.

Ved kreftsykdommer som underliggende dødsårsak var det en relativt stor andel som hadde tilsvarende diagnosekoder i Norsk pasientregister. I Norge er det fra 2010 rutinemessig blitt overfort data fra Norsk pasientregister til Kreftregisteret (9). Kreftregisteret sjekker diagnosekodene i sine databaser mot Norsk pasientregister, og etterspør ekstra informasjon fra sykehusene ved manglende samsvar. Før beslutningen om rutinemessig overføring ble tatt, ble det gjennomført en studie der Norsk pasientregisters data om kreftdiagnosekoder ble sammenstilt med data i Kreftregisteret (10). For alle gruppene av kreftsykdommer som ble undersøkt ble det funnet godt samsvar mellom de to registrene. For noen kreftformer vil det likevel være et spørsmål om man dør av eller med kreftsykdommen. Særlig gjelder dette for dødsfall blant eldre menn med prostatakreft (11).

Fra Sverige er det vist at inklusjon av siste leveårs pasientregisterdata for å bestemme underliggende dødsårsak førte til at denne ble endret ved omtrent $11 \%$ av alle dødsfall, men for bare i underkant av $5 \%$ for kreftdødsfall (12). I en annen svensk studie basert på gjen- nomgang av epikriser for siste sykehusopphold før død er det også vist at kvaliteten av dødsårsaksdata varierer betydelig med dødsårsaksgruppe, med best samsvar for kreftsykdommer (13). Tilsvarende er også vist fra Frankrike. Der var kreft oftest gjenfinnbar som siste hoveddiagnose for personer som hadde dødd på sykehus (14).

Etter hva vi kjenner til er det ikke gjort tilsvarende studier av kontakt med institusjoner innen psykisk helsevern siste leveår, heller ikke internasjonalt. I vår studie fant vi at blant avdøde med voldsomme dødsfall hadde en av fem vært $\mathrm{i}$ kontakt med psykiatrisk institusjon siste leveår. Blant avdøde med psykiske lidelser som underliggende dødsårsak var tilsvarende tall én av 12. Selv om det totale antallet som døde av disse årsakene er lavt, kan det være nyttig å innhente supplerende opplysninger fra psykiatriske institusjoner for å kvalitetssikre de innmeldte dødsårsakene i Dødsårsaksregisteret.

\section{Konklusjon}

Vi har vist at fire av fem personer som døde i perioden 2009-11 var registrert med innleggelse og/eller poliklinisk konsultasjon i somatisk sykehus i løpet av siste leveår, mens én av 20 var registrert med kontakt med psykiatrisk institusjon. Ved manglende eller ufullstendige opplysninger i dødsmeldingen til Dødsårsaks- 
registeret kan data fra Norsk pasientregister benyttes til å undersøke ved hvilke sykehus/ institusjoner avdøde ble behandlet siste leveåret. Denne informasjonen kan så benyttes til å etterspørre supplerende informasjon fra aktuelle sykehus/institusjoner. Det foreligger imidlertid så langt ikke empiriske data på at dette er nyttig. Blant avdøde med ukjent eller uspesifisert dødsårsak er det få som er behandlet på somatisk sykehus/psykiatrisk institusjon siste leveår. Det begrenser den eventuelle nytten av en slik datainnhenting i Dødsårsaksregisterets kvalitetssikringsarbeid.

\section{Inger Johanne Bakken (f. 1968)}

er dr.ing. innen biofysikk og medisinsk teknologi. Hun er seniorrådgiver i registerepidemiologi.

Forfatter har fylt ut ICMJE-skjemaet og oppgir ingen interessekonflikter.

\section{Christian Lycke Ellingsen (f. 1967)}

er spesialist i patologi og overlege ved Dødsårsaksregisteret.

Forfatter har fylt ut ICMJE-skjemaet og oppgir ingen interessekonflikter.

\section{Anne Gro Pedersen (f. 1960)}

er cand.mag. i samfunnsfag og seniorrådgiver ved Dødsårsaksregisteret.

Forfatter har fylt ut ICMJE-skjemaet og oppgir ingen interessekonflikter.

\section{Lilian Leistad (f. 1963)}

er ph.d. innen molekylærmedisin og seniorrådgiver ved Norsk pasientregister. Forfatter har fylt ut ICMJE-skjemaet og oppgir ingen interessekonflikter.

\section{Jonas Minet Kinge (f. 1983)}

er økonom med doktorgrad i helseøkonomi. Han er forsker ved Norsk sykdomsbyrdeprosjekt ved Folkehelseinstituttet og førsteamanuensis ved Avdeling for helseledelse og helse$\varnothing$ øonomi ved Universitet i Oslo.

Forfatter har fylt ut ICMJE-skjemaet og oppgir ingen interessekonflikter.

\section{Marta Ebbing (f. 1963)}

er spesialist i hjertesykdommer, ph.d. i klinisk epidemiologi og avdelingsdirektør ved Avdeling for helseregistre i Folkehelseinstituttet.

Forfatter har fylt ut ICMJE-skjemaet og oppgir ingen interessekonflikter.

\section{Stein Emil Vollset (f. 1955)}

er lege, drPH og professor ved Institutt for global helse og samfunnsmedisin, og leder Norsk sykdomsbyrdeprosjekt i Folkehelseinstituttet. Forfatter har fylt ut ICMJE-skjemaet og oppgir ingen interessekonflikter.

\section{Litteratur}

1. Pedersen AG, Ellingsen CL. Datakvaliteten i Dødsårsaksregisteret. Tidsskr Nor Legeforen 2015; 135: 768-70.

2. Alfsen GC, Lyckander LG. Har kvalitetskontroll av dødsmeldinger i sykehus betydning for dødsårsaksstatistikken? Tidsskr Nor Legeforen 2013; 133: $750-5$.

3. Alfsen GC, Lyckander LG, Lindboe AW et al. Kvalitetssikring ved dødsfall i sykehus. Tidsskr Nor Legeforen 2010; 130: 476-9.

4. Mathers CD, Fat DM, Inoue $M$ et al. Counting the dead and what they died from: an assessment of the global status of cause of death data. Bull World Health Organ 2005; 83: $171-7$

5. FOR-2001-12-21-1476. Forskrift om innsamling og behandling av helseopplysninger i Dødsårsaksregisteret (Dødsårsaksregisterforskriften). http://lovdata.no/dokument/SF/forskrift/2001-12-
$21-1476 ? \mathrm{q}=\mathrm{d} \% \mathrm{C} 3 \% \mathrm{~B} 8 \mathrm{ds} \% \mathrm{C} 3 \% \mathrm{~A} 5 \mathrm{rsaksregister}$ (7.8.2015).

6. Folkehelseinstituttet. Dødelighet og dødsårsaker i Norge gjennom 60 år 1951-2010. Oslo: Nasjonalt folkehelseinstitutt, 2012

7. FOR-2007-12-07-1389. Forskrift om innsamling og behandling av helseopplysninger i Norsk pasientregister (Norsk pasientregisterforskriften). http://lovdata.no/dokument/SF/forskrift/ 2007-12-07-1389?q=norsk+pasientregisterforskriften (7.8.2015).

8. Helsedirektoratet. ICD-10 Den internasjonale statistiske klassifikasjonen av sykdommer og beslektede helseproblemer. Oslo: Helsedirektoratet, 2011

9. Cancer in Norway. 2009. Cancer incidence, mortality, survival and prevalence in Norway. Oslo: Kreftregisteret, 2010.

10. Bakken IJ, Gystad SO, Christensen $\emptyset 0$ et al. Sammenlikning av data fra Norsk pasientregister og Kreftregister. Tidsskr Nor Legeforen 2012; 132: $1336-40$

11. Hernes E, Harvei S, Glattre E et al. High prostate cancer mortality in Norway: influence of Cancer Registry information? APMIS 2005; 113: 542-9.

12. Johansson LA, Westerling R. Comparing hospital discharge records with death certificates: can the differences be explained? J Epidemiol Community Health 2002; 56: 301-8.

13. Johansson LA, Björkenstam C, Westerling R Unexplained differences between hospital and mortality data indicated mistakes in death certification: an investigation of 1,094 deaths in Sweden during 1995. J Clin Epidemiol 2009; 62: 1202-9.

14. Lamarche-Vadel A, Pavillon G, Aouba A et al. Automated comparison of last hospital main diagnosis and underlying cause of death ICD10 codes, France, 2008-2009. BMC Med Inform Decis Mak 2014; 14: 44.

Mottatt 27.6. 2014, første revisjon innsendt 9.12. 2014, godkjent 9.9. 2015. Redaktør: Siri Lunde Strømme. 